\title{
46,XY Differences of Sex Development
}

National Cancer Institute

\section{Source}

National Cancer Institute. 46,XY Differences of Sex Development. NCI Thesaurus. Code C127171.

Differences of sex development in individuals with 46,XY karyotype. 